\title{
ASSESSMENT OF TRAVEL SPEED FOR URBAN STREETS USING GLOBAL POSITIONING SYSTEM
}

\author{
"Sumayah T. Ayob1 \\ Zainab A. Alkaissi ${ }^{1}$ \\ 1) Highway and Transportation Engineering Department, College of Engineering, Mustansiriyah University, Baghdad, Iraq
}

\begin{abstract}
The travel speeds selected and trusted by the driver vary according to his behavior and the surrounding environment. Accordingly, this paper studies the change of the free-flow speed, influences on it, of the route linking Al-Bayaa and Bab Almudam sectors. A GPS device was used to collect data during 60 rounds for three periods (morning, day, and night), 50 of them during the off-peak time and 10 during peak time with drivers of both genders and different ages. The results showed a variation of the FFS values at off-evening peak time, also noting the posted speed limits corresponding to the statistically calculated 85 , which was $69 \mathrm{~km} \backslash \mathrm{hr}$. along the route. The emergence of a significant impact of the security checkpoints in link 3 , causing a general defect in the traffic accounts. Also, there was an increase in the speed with an increase in lane width by $13 \%$ and a decrease in the speed with an increase in the number of lanes by $45.18 \%$ and 18.6\% between 2 and 4 lanes and 2 and 3 lanes respectively. It should be noted that male is bolder and more reckless in choosing speeds by $26.32 \%$ than female and that groups of 50 and below years old choose less speed by $13.52 \%$ of ages 35 and below years old who are more confident and familiar in dealing with roads and choosing the appropriate speed.
\end{abstract}

Keywords: travel speed, FFS, PSL, GPS, driver chrematistics, operation speed.

\section{Introduction}

The great development of urban cities like Baghdad,diversity of land uses, tendency for private mode Caused an increase in traffic volumes[1] ,drivers' behavior to the roads has changed, and the side parking[2] ,all these reasons led to an imbalance in traffic in general, as they affected the flow of free speeds. It is necessary to survey, review these urban rout and to show the influnce of these factors on them.

\subsection{Travel Speed}

In its simplest definition, the travel speed can be defined as the distance traveled between two points on a road divided by the travel time. Which differs from the running speed, including the times of stops and reactions. Thus, any convergence between the two-speed values indicates the smoothness and comfort of the movement [3].

\subsection{Free-Flow Speed FFS}

Free-flow speed (FFS), is known as the freerunning speed that the driver operates for a certain section of roads which are far from traffic control and traffic congestion area, under freeflowing, ideal weather conditions [4,5]. There are many ways for calculate free-flow speed, can be calculated as the post speed limits by adding 5 mph $(8 \mathrm{~km} \mathrm{/} \mathrm{h})$ or from the field geometric features of the road as indicated in the highway capacity manual [4], Nicholas J. Garber third 
edition in 2002 and HCM 2010 indicate that space means speed represents the harmonic mean for a set of vehicle speed is in an inverse relationship with traffic flow, as it became clear that in the case where flows are low, there is less interaction between vehicles, causes the vehicle to travel in a free state and at the maximum possible speed [4,6]. Similarly, the harmonic mean is used to find FFS [7].

\subsection{Factor Affecting the Free-Flow Speed}

Highway capacity manual indicates the factors that directly affecting free-flow speed Which can be summarized as (number and width of the lane, access point, lateral clearance, median type, posted speed limit, horizontal and vertical alignment), A study conducted in Nigeria 2016 [8], showed the presence of additional factors that affect the free flow speed such as weather, vehicle and pedestrian characteristics. And in another study conducted in India [9], it was shown the effect of geometric properties such as horizontal and vertical curves on the selection of free-flow speed, another local research proves this [10]. Moreover, in a study conducted on several drivers of different ages and from bothgenders, it revealed the extent of the impact of these two characteristics to reduce the operating speed of the road [11].

\subsection{Posted Speed Limits PSL and the Relationship with FFS}

It is the speed declared on the sides of the road, which mainly depends on the $85^{\text {th }}$ percentile speed [12], most drivers make reasonable and wise estimates of appropriate road speeds, which are often consistent with the design geometric features of the road. The MUTCD [13] shows the relationship between the posted speed and the FFS. When the speed limit is declared, it should be within $5 \mathrm{MPH}$ of the 85 th percentile speed in the case of the traffic being in a state of free flow.

\subsection{5 $^{\text {th }}$ Percentile Speed and the Relation with Posted Speed Limit PSL}

It is the speed that most vehicles travel on a road under perfect and free-flow traffic conditions without the influence of the weather, abnormal and slow traffic movements. This speed is chosen by the drivers, considering that it is the safest speed, therefore $85^{\text {th }}$ percentile speed is the main indicator for choosing speed limits for the nearest 5 miles (10 km\hr.) [14].

\subsection{Road Classification}

The road network of urban cities has a great diversity in terms of the engineering design on which the road is designed based and in terms of the actual functional classification of the road. For various previous studies, the methods were functionally classified into four categories: (principal arterial, minor arterial, and collector, local) $[15,16]$. This is what the federal highway administration FHWA has indicated and it was agreed with AASHTO. However, this classification does not give a clear indication of the roads because the classification is based on traffic volumes, the number of miles served by the road, and the nature of the service it provides in terms of mobility and accessibility. Highway capacity manual HCM (2010) clarified this problem and gave other, more precise criteria for classification through the different categories based on design and function to give a more realistic classification for the road [4]. This classification, which the HCM has followed, takes the free flow speed FFS as the basis for knowing the class of road.

\subsection{The Utilize of GPS Technique in Data Collection}

Finding values for the speeds operated by driver on a particular road with great accuracy and abundance of data, in addition to the use of modern technology methods such as the global positioning system GPS which saves effort and 
time, GPS technique is used. Recently published research [17, 18]. Demonstrated this fact. Moreover, other researchers use the GPS technique mainly to calculate travel speeds [19] With the development of data extracted from it, it became the most common method for collecting research data [20 \& 21].

\section{Objective of the Research}

- Extrapolation of a method for calculating the free flow speed along a path based on the acquired data.

- Investigate the impact of the driver's characteristics in terms of age and gender, the number of lanes, and the width of each lane on the free-flow speed.

- Explore the functional classification of some urban street in Baghdad city, which have major activities and different land uses.

\section{Methodology}

To understand the FFS nature in the city of Baghdad, it is logical to resort the roads that serve different traffic-generating regions with different land uses, in addition to different geometric features used by a large variety of drivers to demonstrate the effect of the aforementioned factors on changing the values of travel speed patterns. Given this, the path linking two vital areas in Baghdad was chosen, namely Bab alMuadam and al-Bayaa areas in both directions, which in turn connects the two sectors of Baghdad al-Karkh and Al-Rusafa with a total length of 11,532 km "Image .1". This path passes through 14 links. Each link has different engineering characteristics from the other and has widely different land uses on both sides of the road, as explained in "Table. 1".
In this research, determining free-flow speed requires knowledge of the case in which the flow is free. Accordingly, the route was studied at the times of the morning, afternoon, and evening offpeak in the period of $(9: 00 \mathrm{am}-12: 30 \mathrm{pm}),(3: 00$ $\mathrm{pm}-5: 30 \mathrm{pm}),(7: 30 \mathrm{pm}-10: 00 \mathrm{pm})$ respectively, on Mondays, Tuesdays, and Wednesdays of every week during which traffic is uniform, for 4 weeks (December /2020) To extract 60 sample size 30 for each direction, which represents the minimum speeds sample size to be normally distributed [22]. These periods were determined based on a test tour throughout the whole day for the study area and also after reviewing some local studies of some links that confirmed the validity of choosing times for off-peak periods.

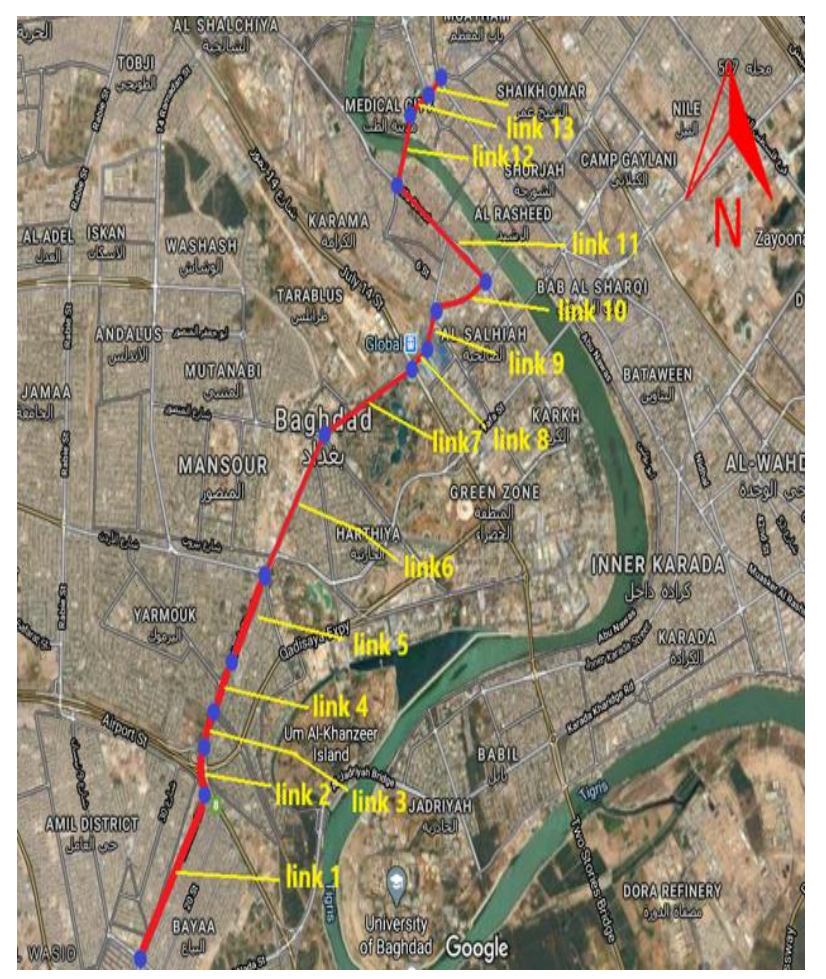

Image 1. Arial photo of the study area 
Table 1. Link characteristics

\begin{tabular}{|c|c|c|c|c|c|c|c|c|}
\hline \multirow[t]{2}{*}{ link } & \multirow[t]{2}{*}{ Name } & \multirow[t]{2}{*}{$\begin{array}{l}\text { Length } \\
\text { (meter) }\end{array}$} & \multicolumn{2}{|c|}{$\begin{array}{l}\text { No. of a lane } \\
\text { (One direction) }\end{array}$} & \multicolumn{2}{|c|}{$\begin{array}{l}\text { Lane width } \\
\text { (meter) }\end{array}$} & \multicolumn{2}{|c|}{$\begin{array}{l}\text { Posted speed } \\
\text { limits (PSL) }\end{array}$} \\
\hline & & & north & south & north & south & north & south \\
\hline 1 & Mumtaz street & 1940 & 3 & 3 & 3.4 & 3.4 & 60 & 60 \\
\hline 2 & Jinub street & 390 & 2 & 2 & 3 & 3 & 50 & 50 \\
\hline 3 & Al Yarmouk Street I & 650 & 3 & 4 & 3.4 & 3.6 & 40 & 60 \\
\hline 4 & Al Yarmouk bridge & 470 & 2 & 2 & 3 & 3 & 60 & 60 \\
\hline 5 & Al Yarmouk street II & 930 & 3 & 3 & 3.6 & 3.6 & 40 & 40 \\
\hline 6 & Damascus street & 1530 & 3 & 3 & 3.6 & 3.6 & 60 & 60 \\
\hline 7 & Damascus street & 1390 & 3 & 3 & 3.6 & 3.6 & 60 & 60 \\
\hline 8 & Al Allawi I & 560 & 3 & 3 & 3.6 & 3.6 & 40 & 40 \\
\hline 9 & Al Allawi II & 200 & 4 & 4 & 3.4 & 3.4 & 40 & 40 \\
\hline 10 & Al Nasser Street & 760 & 6 & 6 & 3.4 & 3 & 60 & 60 \\
\hline 11 & Haifa street & 1532 & 3 & 3 & 3.4 & 3.4 & 60 & 60 \\
\hline 12 & Bab Almada bridge & 900 & 2 & 2 & 3 & 3 & 60 & 60 \\
\hline 13 & Bab almudam I & 80 & 3 & 3 & 3 & 3 & 60 & 60 \\
\hline 14 & Bab almudam II & 200 & 3 & 3 & 3 & 3 & 60 & 60 \\
\hline
\end{tabular}

Moving vehicle technology was used to compute traffic flow rate during the periods mentioned above. The headway was also deduced, which represents the inverted free-flow [23]. The first researcher implemented this method is John Glen Wardrop, 1954 [24]. A study from William J. Mortimer [25] came after that showed how close this method of estimation is to reality. At the same time, GPS was used to calculate the speeds. It was connected with the vehicle. Then, the control bottom was activated when entering the route of the study, shown in "Image. 2" and the results of the device appear from the device to the server, which gives the vehicle's movement details every 10 seconds, with the location and coordinates "Image. 3 " as shown in Tables:

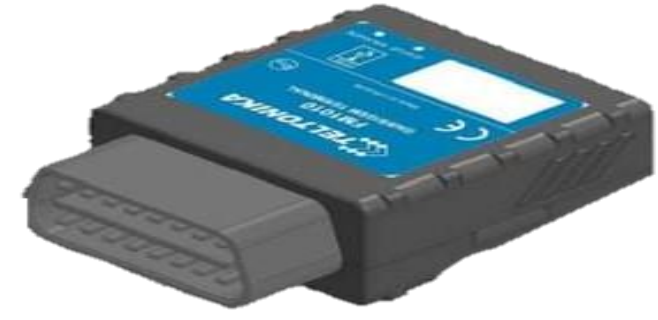

Image 2. GPS device

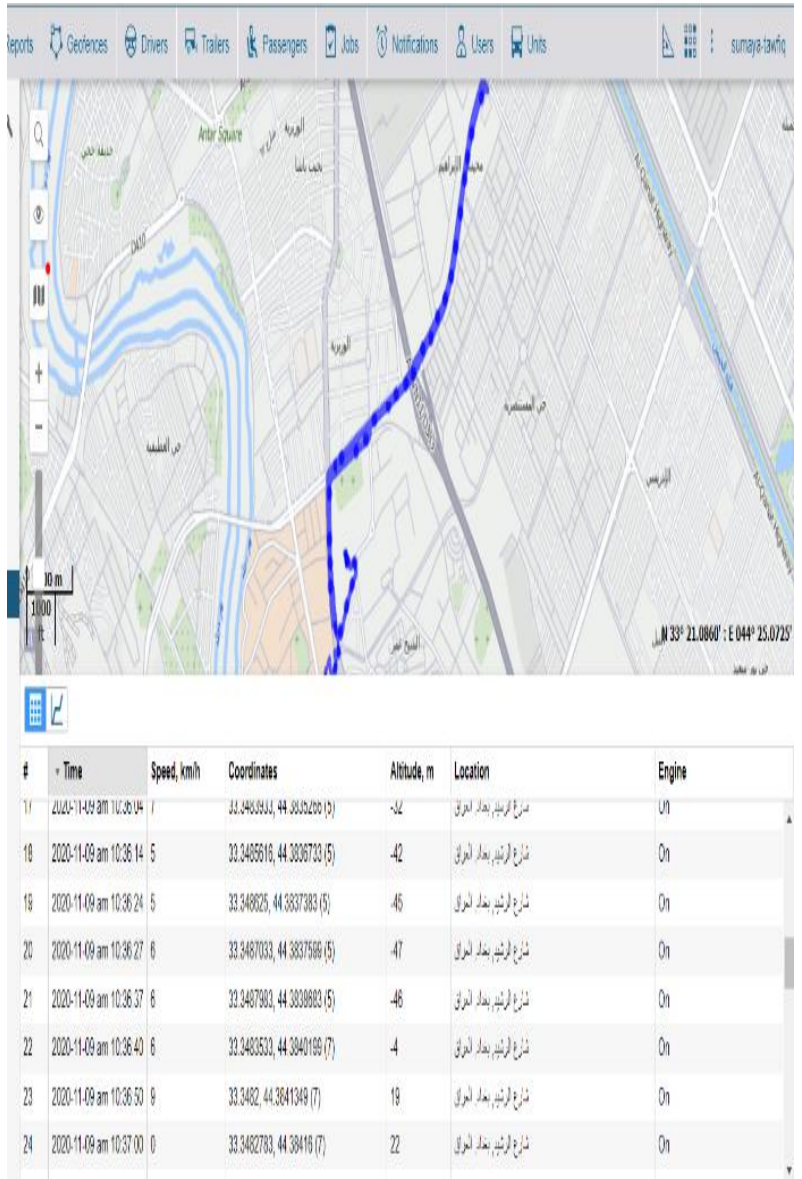

Image 2. GPS device output 
Table 2. Outcomes for the morning off-peak period (9:00 am - 12:30 pm)

\begin{tabular}{|c|c|c|c|c|c|c|}
\hline \multirow[b]{2}{*}{ link } & \multicolumn{3}{|c|}{ north } & \multicolumn{3}{|c|}{ South } \\
\hline & $\begin{array}{l}\text { Operation speed } \\
\text { (km\hr.) }\end{array}$ & $\begin{array}{c}\text { Flow rate } \\
\text { (veh } \backslash h r .)\end{array}$ & $\begin{array}{l}\text { headway } \\
\text { (sec.) }\end{array}$ & $\begin{array}{l}\text { Operation speed } \\
\text { (km\hr.) }\end{array}$ & $\begin{array}{l}\text { Flow rate } \\
\text { (veh. Ihr.) }\end{array}$ & $\begin{array}{l}\text { headway } \\
\text { (sec.) }\end{array}$ \\
\hline 1 & 59 & 1239 & 3 & 67 & 1317 & 3 \\
\hline 2 & 52 & 495 & 7 & 58 & 474 & 8 \\
\hline 3 & 18 & 1125 & 3 & 53 & 1102 & 7 \\
\hline 4 & 53 & 398 & 9 & 59 & 427 & 8 \\
\hline 5 & 56 & 903 & 4 & 57 & 892 & 4 \\
\hline 6 & 48 & 969 & 4 & 55 & 1047 & 3 \\
\hline 7 & 47 & 1110 & 4 & 41 & 532 & 5 \\
\hline 8 & 39 & 1384 & 3 & 31 & 1090 & 3 \\
\hline 9 & 46 & 1500 & 2 & 41 & 1531 & 2 \\
\hline 10 & 52 & 909 & 4 & 43 & 838 & 4 \\
\hline 11 & 51 & 958 & 4 & 50 & 1013 & 4 \\
\hline 12 & 56 & 829 & 4 & 53 & 852 & 4 \\
\hline 13 & 32 & 629 & 6 & 32 & 657 & 6 \\
\hline 14 & 18 & 719 & 5 & 17 & 704 & 5 \\
\hline
\end{tabular}

Table 3. Outcomes for the afternoon off-peak period (3:00 pm- 5:30 pm)

\begin{tabular}{|c|c|c|c|c|c|c|}
\hline \multirow[b]{2}{*}{ link } & \multicolumn{3}{|c|}{ north } & \multicolumn{3}{|c|}{ south } \\
\hline & $\begin{array}{l}\text { Operation speed } \\
\text { (km)hr.) }\end{array}$ & $\begin{array}{l}\text { Flow rate } \\
\text { (veh. } \backslash \mathrm{hr} \text {.) }\end{array}$ & $\begin{array}{l}\text { headway } \\
\text { (sec.) }\end{array}$ & $\begin{array}{l}\text { Operation speed } \\
(\mathrm{km} \backslash \mathrm{hr} .)\end{array}$ & $\begin{array}{l}\text { Flow rate } \\
\text { (veh. Ihr.) }\end{array}$ & $\begin{array}{l}\text { headway } \\
\text { (sec.) }\end{array}$ \\
\hline 1 & 56 & 1141 & 3 & 62 & 1097 & 3 \\
\hline 2 & 60 & 413 & 9 & 56 & 451 & 8 \\
\hline 3 & 45 & 1227 & 3 & 49 & 1158 & 3 \\
\hline 4 & 61 & 494 & 7 & 63 & 496 & 7 \\
\hline 5 & 59 & 950 & 4 & 56 & 918 & 4 \\
\hline 6 & 55 & 801 & 5 & 49 & 815 & 4 \\
\hline 7 & 51 & 766 & 9 & 38 & 699 & 5 \\
\hline 8 & 49 & 986 & 4 & 28 & 1207 & 3 \\
\hline 9 & 49 & 1521 & 2 & 38 & 1451 & 2 \\
\hline 10 & 57 & 469 & 8 & 38 & 435 & 8 \\
\hline 11 & 56 & 967 & 4 & 57 & 949 & 4 \\
\hline 12 & 61 & 701 & 5 & 63 & 671 & 5 \\
\hline 13 & 38 & 598 & 6 & 41 & 530 & 7 \\
\hline 14 & 48 & 576 & 6 & 49 & 625 & 6 \\
\hline
\end{tabular}

Table 4. Outcomes for the evening off-peak period (7:00 pm -10:00 pm)

\begin{tabular}{ccccccc}
\hline link & $\begin{array}{c}\text { Operation speed } \\
\text { (kmlhr.) }\end{array}$ & $\begin{array}{c}\text { north } \\
\text { Flow rate } \\
\text { (veh.lhr. })\end{array}$ & $\begin{array}{c}\text { headway } \\
\text { (sec.) }\end{array}$ & $\begin{array}{c}\text { Operation speed } \\
(\text { kmlhr. })\end{array}$ & $\begin{array}{c}\text { south } \\
\text { Flow rate } \\
\text { (veh.lhr.) }\end{array}$ & $\begin{array}{c}\text { headway } \\
\text { (sec.) }\end{array}$ \\
\hline 1 & 73 & 384 & 10 & 77 & 401 & 9 \\
2 & 61 & 363 & 10 & 64 & 354 & 10 \\
3 & 48 & 432 & 8 & 56 & 428 & 8 \\
4 & 62 & 363 & 10 & 63 & 355 & 10 \\
5 & 61 & 1014 & 4 & 55 & 1030 & 3 \\
6 & 62 & 1092 & 3 & 61 & 1016 & 4 \\
7 & 68 & 1234 & 3 & 67 & 1253 & 3 \\
8 & 57 & 893 & 4 & 53 & 754 & 8 \\
9 & 57 & 472 & 8 & 58 & 423 & 9 \\
10 & 62 & 389 & 9 & 51 & 381 & 9 \\
11 & 61 & 461 & 8 & 62 & 455 & 11 \\
12 & 62 & 346 & 10 & 63 & 329 & 10 \\
13 & 59 & 338 & 11 & 63 & 348 & 12 \\
14 & 60 & 282 & 13 & 62 & 315 & \\
\hline
\end{tabular}


These data represent the arithmetic average for a total of 50 samples for the speed, 18 test runs for each of the morning and evening off-peak periods, and the rest 14 test runs for Off-peak daytime. As for the traffic flow rate, flow samples were taken at the same times as the speed samples, but more broadly, as four samples were taken for one test run in each link, meaning a total of 72 samples per run per period. After that, other samples were taken for 5 drivers of different ages and both-genders "Table.5" And Additional data set were collected to know the effect of the road characteristics (lane width and the number of lanes) on the operating speed of the driver at times of free traffic flow.

Table 5. Driver characteristics

\begin{tabular}{lll}
\hline driver & Gender & age \\
\hline A & male & 50 \\
B & male & 41 \\
C & male & 35 \\
D & Male & 32 \\
F & Female & 25 \\
\hline
\end{tabular}

\section{Results and Discussions}

The results of the data extracted from the GPS showed in "Table .4", that the free-flow status is achieved at the time of the evening when the traffic flow is less than 500 vehicles per hour, and the headway is greater than 7 seconds [3].

"Fig .1" exhibits an almost seamless form of operational speed profile along the path.

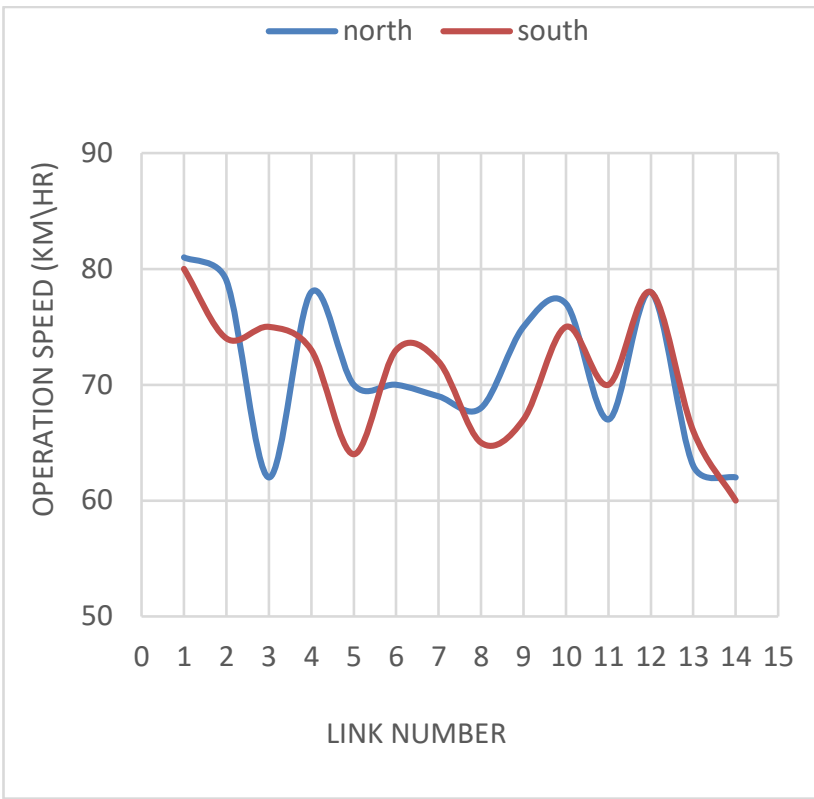

Figure 1. Operation speed profile

Accordingly, the calculation of the free-flow speed of each link is by converting the GPS data that represents the speed during a specific period (time mean speed.) into space mean speed by taking the variance depending on the relationship between them as explained by Garber third edition in 2002:

$$
\begin{aligned}
& \overline{u_{t}}=\overline{u_{s}}+\frac{\sigma}{\overline{u_{s}}} \\
& \overline{u_{t}}=\frac{\overline{u_{s}^{2}}-\sigma}{\overline{u_{s}}} \\
& \overline{u_{s}^{2}}-\overline{u_{t} \overline{u_{s}}}+\sigma=0
\end{aligned}
$$

Where:

$\overline{u_{s}}$ : Space mean speed

$\overline{u_{t}}$ : Time mean speed

$\sigma:$ Variance 
Table 6. Free-flow speed

\begin{tabular}{ccccccc}
\hline link & \multicolumn{3}{c}{ evening period } & south & \\
\cline { 2 - 7 } & $\overline{u_{t}}$ & $s^{2}$ & $\overline{u_{s}}$ & $\overline{u_{t}}$ & $s^{2}$ & $\overline{u_{s}}$ \\
1 & 73 & 17.361 & 72.8 & 77 & 30.44 & 76.6 \\
2 & 61 & 20.54 & 60.7 & 64 & 25.944 & 63.6 \\
3 & 48 & 372.19 & 38.3 & 56 & 59.2 & 54.9 \\
4 & 62 & 44.278 & 61.3 & 63 & 31.944 & 62.5 \\
5 & 61 & 40.027 & 60.3 & 55 & 37 & 54.3 \\
6 & 62 & 46 & 61.2 & 61 & 34.694 & 60.4 \\
7 & 68 & 19.44 & 67.7 & 67 & 25.75 & 66.6 \\
8 & 57 & 81.694 & 55.5 & 53 & 39.25 & 52.2 \\
9 & 57 & 27.25 & 56.5 & 58 & 11 & 57.8 \\
10 & 62 & 17.25 & 61.7 & 51 & 5.527 & 50.9 \\
11 & 61 & 8.194 & 60.9 & 62 & 47.5 & 61.2 \\
12 & 62 & 17.25 & 61.7 & 63 & 29.5 & 62.5 \\
13 & 59 & 37.0278 & 58.4 & 63 & 10.6944 & 62.8 \\
14 & 60 & 15.02 & 59.7 & 62 & 20.5 & 61.7 \\
\hline
\end{tabular}

By conducting a statistical analysis of the output data from the GPS device for each link using Statistical Package for the Social Sciences SPSS, the values of $85^{\text {th }}$ percentile speed, $95^{\text {th }}$ percentile speed, and other descriptive statical characteristics were calculated as shown in "Table. 7".

Table 7. Statical analysis

\begin{tabular}{cccccccc}
\hline link & Mean & Median & Mode & Std. Deviation & Variance & $85^{\text {th }}$ percentile speed & $9^{\text {th }}$ percentile speed \\
\hline 1 & 66.06 & 65.5 & 64 & 9.63711 & 92.874 & 75 & 81.8 \\
2 & 58.56 & 60 & 60 & 6.42749 & 41.313 & 64 & 70 \\
3 & 43.81 & 48 & 56 & 17.30042 & 299.305 & 60 & 65 \\
4 & 60.29 & 61 & 60 & 9.15112 & 83.743 & 68 & 75 \\
5 & 57.6 & 56.5 & 48 & 7.29271 & 53.184 & 64 & 70.9 \\
6 & 55.2 & 58 & 56 & 12.27574 & 150.694 & 65.35 & 69.45 \\
7 & 52.58 & 53 & 48 & 14.78843 & 218.698 & 70 & 73.45 \\
8 & 43.14 & 43.5 & 32 & 14.39389 & 207.184 & 60 & 62.45 \\
9 & 48.6 & 49 & 48 & 9.9857 & 99.714 & 59.35 & 61.9 \\
10 & 50.88 & 52 & 48 & 9.12559 & 83.276 & 60 & 65.5 \\
11 & 56 & 56 & 56 & 6.50902 & 42.367 & 63.35 & 66.45 \\
12 & 59.41 & 60 & 60 & 6.43855 & 41.455 & 66.5 & 68 \\
13 & 44.72 & 40 & 30 & 13.41343 & 179.92 & 63.35 & 67 \\
14 & 41.92 & 48.5 & 15 & 19.59783 & 384.075 & 61 & 67.45 \\
\hline
\end{tabular}


The result shows the effect of the characteristics of the driver and the road in choose the operating speed along the path. The bar chart "Fig. 2" shows the variation of the operating speed for different ages of drivers along the route and at the same time, where it is noticed that the drivers are in the age period between 35-50 years old are more familiar with the roads and gutsier in running vehicles at high speed on each link. Similar to older drivers, who are more rational and wiser in choosing their speeds, younger ages are usually unfamiliar with road handling. "Fig. 3" shows that Women are less daring and more cautious than men this is normal, due to the physiological nature of the women.

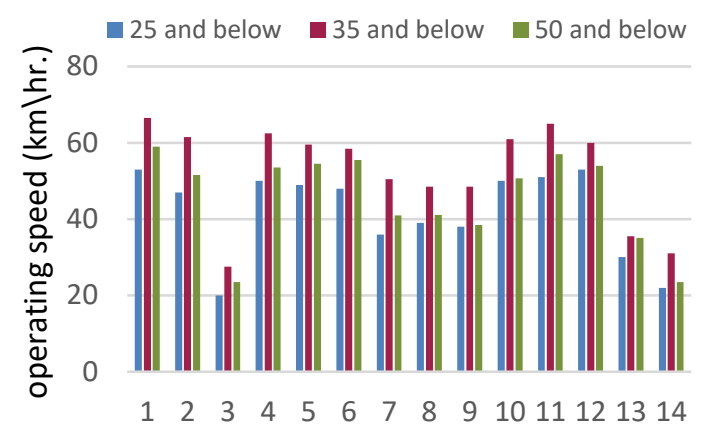

Figure 2. Operating speed variation with driver age

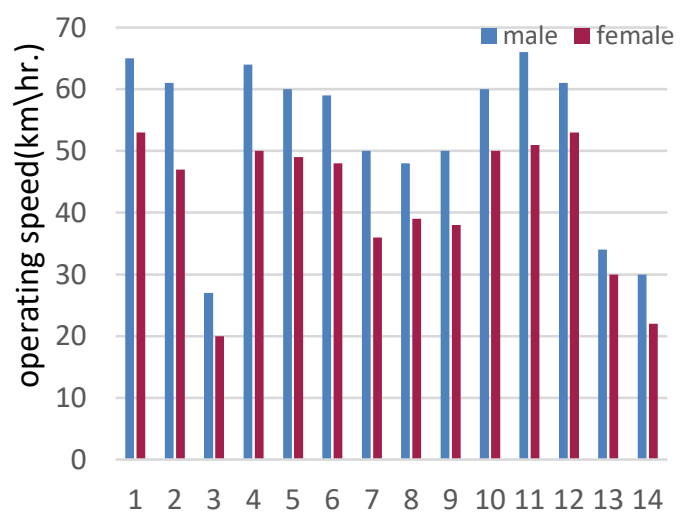

Figure 3. Operating speed variation with driver gender
At the other side, it can be found that the geometrical properties of the links also have a high impact as they are placed in "Fig. 4" \& "Fig. 5".

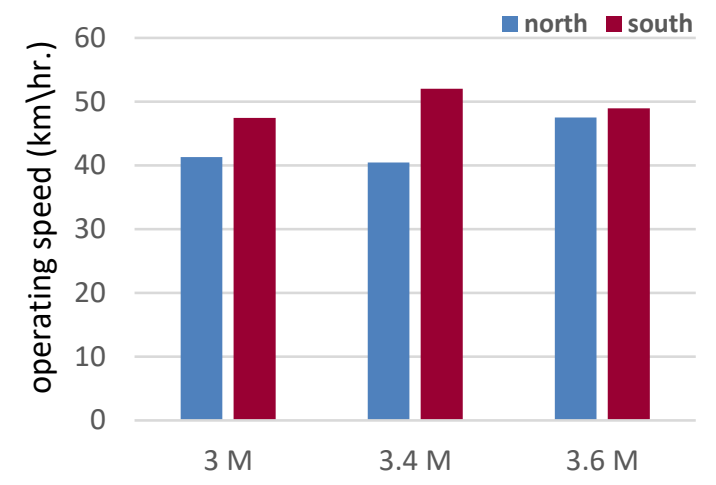

Figure 4. Operating speed variation with lane width

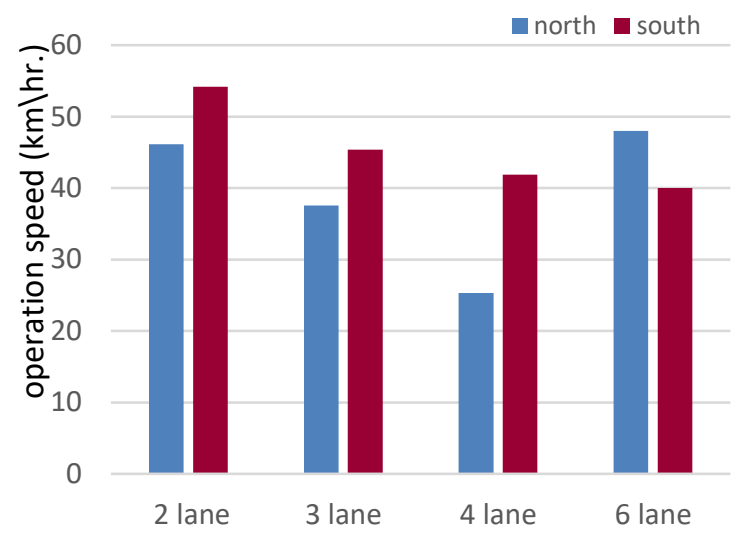

Figure 5. Operating speed variation with no. of lanes

Accordingly, the free-flowing speed was calculated during the off-peak evening time shows in "Table .6", was functionally reclassified using the aforementioned determinants in highway capacity manual 2010 appeared that a clear difference was evident between the resulting classification and the classification adopted by the Municipality of the capital, Baghdad "Table.8". 
Table 8. Functional classification of links according to HCM

\begin{tabular}{ccccc}
\hline Link & Functional category & Design category & FFS & Urban street class \\
NO. & Principle arterial & Intermediate & 76.6 & I \\
\hline 1 & Minor arterial & Suburban & 63.6 & II \\
2 & Minor arterial & Urban & 54.9 & IV \\
3 & Minor arterial & Intermediate & 62.5 & II \\
4 & Minor arterial & Intermediate & 54.3 & III \\
5 & Principle arterial & Intermediate & 60.4 & II \\
6 & Principle arterial & Intermediate & 66.6 & II \\
7 & Principle arterial & Urban & 52.2 & III \\
8 & Principle arterial & Urban & 57.8 & III \\
9 & Minor arterial & intermediate & 50.9 & III \\
10 & Principle arterial & Intermediate & 61.2 & II \\
11 & Principle arterial & Intermediate & 62.5 & II \\
12 & Principle arterial & Urban & 62.8 & III \\
13 & Principle arterial & Urban & 61.7 & III \\
14 & & &
\end{tabular}

Table 9. Comparison classification

\begin{tabular}{ccc}
\hline Link no. & Functional classification of Iraq Municipality & Functional classification of HCM \\
\hline 1 & Principle distribution TSO1 & Principle arterial class I \\
2 & Principle distribution TSO1 & Minor arterial class II \\
3 & Principle distribution TSO1 & Minor arterial class IV \\
4 & Principle distribution TSO1 & Minor arterial class II \\
5 & Principle distribution TSO1 & Minor arterial class III \\
6 & Principle distribution TSO1 & Principle arterial class II \\
7 & Principle distribution TSO1 & Principle arterial class II \\
8 & Principle distribution TSO1 & Principle arterial class III \\
9 & Principle distribution TSO1 & Principle arterial class III \\
10 & Principle distribution TSO1 & Minor arterial class III \\
11 & Principle distribution TSO1 & Principle arterial class II \\
12 & Principle distribution TSO1 & Principle arterial class II \\
13 & Principle distribution TSO1 & Principle arterial class III \\
14 & Principle distribution TSO1 & Principle arterial class III \\
\hline
\end{tabular}

From the results mentioned above, some observations must be explained:

- The presence of a fixed security checkpoint at Link 3 towards the north. This condition causes an abnormal traffic situation, and this disruption is evident in the data.

Link 10 has 6 lanes. The clarification of this is that traffic has been banned in two directions and that the whole northern link serves one-way traffic for security provisions, whereas, roads with 6 lanes are usually highways or expressways which is not available in urban cities.

- Link 5, 6 and 7 are concentrated in areas with diverse and vital land uses, such as the presence of health, educational, and government institutions that generate high demand at times of the day. In addition, the presence of entertainment centers, shopping centers generate traffic jams. So, these links are not subject to a state of free flow throughout the day and this is what was shown in the presented results. 
- There is a noticeable effect of the side parking of most links on the operating speed. Thereby, the number of lanes of the road is reduced, which negatively affects its operation.

- In areas with a number of two lanes where the driver is restricted to movement within the lane without overtaking the adjacent lane, provides a stable operating speed and safety along the road that differs from what has been noticed on roads where the 3 or 4 lanes with $3.6 \mathrm{~m}$ width, in which the driver exceeds the adjacent lane so that the 3-lane road becomes occupied by 4 vehicles.

- From "Fig. 5", a decrease in operational speeds is observed when the number of lanes is increased. This effect is due to on - street parking [2] that are available in the links with a number of 3-lanes or more, which often distract the driver and affect the reaction time. This feature is devoid of the 2-lane links.

\section{Conclusion and Recommendation}

Depending on the results obtained from the field study:

- The last classification of roads in Baghdad, done by Scott Wilson Kirkpatrick and partners in 1980, is different from the classification that the results indicated as shown in (junub St., Al Yarmouk I \&II streets, Al Yarmouk Bridge, Al Allawi I\&II streets, AL Nasser St., Bab Almudam I \&II streets).

- Notice that there is a slight discrepancy between the free-flow speed of the links between the northern and southern directions, except for link number 3, which contains a security checkpoint in the northern direction.
- The results show that the vehicles operate at a faster speed under the control of males than in females, at a rate of $26.32 \%$.

- The travel speed for drivers aged between 5035 years is $13.52 \%$ less than ages $25-35$ and more by $8.37 \%$ from 25 years and below.

- The speed increases with the increase in the lane width by $13 \%$ when comparing a 3 meter and a 3. 6-meter lane width.

- The bar charts showed a decrease in the rate of speed by increasing the number of lanes by $45.18 \%$ between 2 and 4 lanes and by $18.6 \%$ between 2 and 3 lanes.

- Damascus Street does not reach a state of free traffic throughout the day.

- The statistical analysis showed that there is a high dispersion between the data of the links, and there was also a correlation between the design speed and the 85-percentile speed which is $69 \mathrm{~km} / \mathrm{hr}$. at evening peak period along the total selected route.

- The average speed of the southern direction is higher than the northern direction, as the north direction represented in $\mathrm{Bab}$ alMoadham sector, which represents the CBD of Baghdad city, with high attraction rate for travel compared to Al- Bayaa sector.

- From what was previously noted, preventing illegal On-side parking, encouraging people to use public transportation and distributing various activities in separate areas within the city, all of these proposals help to significantly improve the traffic situation in the city of Baghdad.

\section{Acknowledgment}

Many thanks to Mustansiriyah University, the college of engineering, the highway and transportation department which contributed to the completion of this research. 


\section{Conflict of Interest}

The authors confirm that the publication of this article causes no conflict of interest.

\section{References}

1. Noor, M. A., Namir, G. A. (2019). "The influence change of private car ownership on patterns of mode choice in Baghdad city". 2nd International Conference on Sustainable Engineering Techniques (ICSET) DOI:10.1088/1757899X/518/2/022025. pp.1.

2. Edquist, J., Rudin-Brown, C. M., and Lenné, M. G. (2012). "The effects of on-street parking and road environment visual complexity on travel speed and reaction time". Accident Analysis and Prevention, 45, doi: 10.1016/j.aap.2011.10.001 .pp. 759-765.

3. Ahmed, F. A. (2016)."Traffic speed analysis: spot speed, travel speed \& speed". 1004137 Department of civil engineering, Bangladesh University of Engineering and Technology. pp.9.

4. Transportation Research Board, Highway Capacity Manual (HCM) (2000), 'Urban street concept", national research council. ch.10. pp.17.

5. Lee, V. L. (2020). "The development and assessment of free-flow speed models under heterogeneous traffic in facilitating sustainable inter-urban multilane highways". Sustainability, 12(8), 3445, pp. 1-3.

6. Nicholas, J. G. (2002). 'Traffic and highway engineering". University of Virginia. Ch.6p.215-217.

7. Matthew, D. D. (2011). "Estimating freeflow speed from posted speed limit signs". 6th International Symposium on Highway
Capacity and Quality of Service Stockholm, Sweden. pp.307.

8. Ibrahim, T. Y. and Oluwafemi, O. A. (2016). 'The factors that affect the free flow speed on an arterial in Ilorin ". Nigerian Journal of Technology (NIJOTECH) Vol. 35, No. 3. Nigerian. pp. $473-480$.

9. Transportation Research Board. (2011) "Operation speed modelling". Number EC151.90

10. Ayman, A. A., Gandhi G. S. (2008). "Development of models for predicting speed on horizontal curve for two-lane rural highway". The Arabian Journal for Science and Engineering, Volume 33, Number 2B.pp.374.

11. Teo, S. H. (2016). 'Speeding driving behaviour: age and gender experimental analysis". MATEC Web of Conferences 74, 00030. p.1.

12. Federal Highway Administration. (1996). "Understanding design, operating, and posted speed". Texas Department of transportation, Report No.1465-1. pp.12.

13. Federal Highway Administrator. (2009). "The manual on uniform traffic control devices"(MUTCD). pp.50.

14. Roger, P. R., Elena, S.P., \& William, R. M. (2004). "Traffic engineering". Third edition. The United States of America, by Pearson Education. pp.204 \& 428.

15. FHWA federal highway administration. (2013). "Highway functional classification: concept, criteria and procedure". p.14-17.

16. American Association of State Highway and Transportation Officials (AASHTO). (2010). "A Policy on geometric design of highways and street". 444 North Capitol Street, NW, Suite 249. Washington, DC 20001, 1-12. 
17. Khaled, H. (2002). 'Travel time, speed, and delay analysis using an integrated GIS/GPS". Can. J. Civ. Eng. Vol. 29.

18. Federal Highway Administration. (2000). Research development and technology. "An investigation of the use of global positioning system (GPS) and it is augmentation with state and local transportation department". Publication no. FHWA-RD-00-093.

19. Mohammad, T. O. (2013). "GPS vehicle tracking in urban areas". Conference paper. 20. Zainab, A. K., Ali, J. K., and Estabraq, F. A. (2021). "Travel time prediction models for major arterial road in Baghdad city using manufactured GPS device ". IOP Conf. Series: Materials Science and Engineering. Vol. 1090. Pp.2.

21. Zainab, A. A., Hussain, R. Y. (2019)." Delay time analysis and modelling of signalised intersections using global positioning system (GPS) receivers". IOP Conference Series: Materials Science and Engineering, Volume 671, 3rd International Conference on Engineering Sciences 4-6, Karbala, Iraq.

22. V. Varsha, Gaurav, H.P. K. R. Reo, B.K. Bindhu, (2014). "Determination of sample size for speed measurement on urban arterials". 11th Transportation Planning and Implementation Methodologies for Developing Countries, TPMDC. Transportation Research Procedia 17 pp.384 -390 .

23. Jostin, k., Lall.1997."ttransportation engineering ". Second edition. Prentice Hall.

24. John, G. W. (1954)." A method of estimating speed and flow of traffic from a moving vehicle". pp.159

25. William, J. M. (1955). "Moving vehicle method of estimating traffic volumes and speeds". pp.16. 